\title{
Tolerance of noncompliance: Discretion rather than simple rules?*
}

Tolerancia al incumplimiento: ¿discreción en lugar de reglas simples?

\author{
Álvaro ForTEZA** \\ Cecilia NobOA***
}

\begin{abstract}
We argue that societies sometimes choose not to enforce the law to gain "flexibility". Especially developing countries face a dilemma between discretion and commitment to only partially-contingent rules. Rules are good for incentives, but discretion may be more "flexible". We embed this dilemma in a political model and show that citizens will not support strong enforcement institutions unless the state is able to commit to sufficiently sophisticated redistributive policies.
\end{abstract}

Key words: Discretion, commitment, simple rules, informality, enforcement.

JEL Classification: D71, D81, E26, 017.

\section{Resumen}

Argumentamos que existen ocasiones en que las sociedades pueden elegir no hacer cumplir la ley para ganar "flexibilidad". En particular, los países en desarrollo se enfrentan a un dilema entre discreción y compromiso a reglas parcialmente contingentes. Las reglas son buenas en términos de incentivos, pero la discreción brinda "flexibilidad". Enmarcamos este dilema en un modelo político y mostramos que los ciudadanos no apoyan la aplicación de una fiscalización

* Comments by Juan Pereyra, Jorge Ponce, Ianina Rossi and two anonymous referees from Estudios de Economía were very useful in revising this paper. We also appreciate comments received from participants at the 2014 International Economics Association World Congress, the 2014 LACEA meeting and seminars at dECON-FCS-UDELAR and Universidad de Montevideo. The usual disclaimer applies.

**Departamento de Economía, FCS-UDELAR, Uruguay. alvaro.forteza@ cienciassociales. edu.uy

*** Departamento de Economía, FCS-UDELAR, Uruguay. cecilia.Noboa@ cienciassociales. edu.uy

Received: April, 2018. Accepted: September, 2018. 
fuerte a menos que el Estado pueda comprometerse a políticas redistributivas suficientemente sofisticadas.

Palabras clave: Discreción, compromiso, reglas simples, informalidad, fiscalización.

Clasificación JEL: D71, D86, E26, $O 17$.

\section{INTRODUCTION}

In developing countries, economic and social policies often seem to be conducted on a discretionary basis. Governments seem to be unable or unwilling to tie their hands following well established formal rules (Holland 2014a, b, 2016). In the present paper, we provide a formal model to analyze the discretioncommitment dilemma that arises when neither private firms nor the government itself can provide full protection on a pre-committed basis. Governments that are unable or unwilling to enforce the law generate a gap between de jure and de facto policies and generate large distortions ${ }^{1}$.

We present in the main text a model of a benevolent government operating under two exogenously given policy regimes. Under a commitment regime, the government can commit to a relatively simple or unsophisticated social protection policy. In the presence of moral hazard, this policy provides the right incentives, but with possibly too much risk. In a discretionary regime, the benevolent government cannot credibly announce anything else than full insurance. As a result, incentives are strongly distorted. There is thus a non-trivial tradeoff and, in some cases, discretion is better than commitment.

One possible reason behind the limited state capacity to provide formal precommitted social protection is that governments may not know the probability of occurrence of some outcomes. If this is the case, it may not be possible to set formal insurance programs because, among other reasons, it is not possible to design and budget a formal program in this environment with Knightian uncertainty (Knight 1921) ${ }^{2}$. But if commitment institutions are not present, governments can act ex-post on a discretionary basis.

A complementary reason is that some outcomes may not be verifiable by a court, even if they are ex-post observable by everybody. If this is the case, formal social protection cannot be based on those outcomes and pre-committed rules

1 The gap between de jure and de facto policies and institutions is receiving considerable attention in recent literature (Feld and Voigt 2003; Foldvari 2015; Mainwaring and Welna 2003; O’Donnell 1998, Van de Walle 2001; Voigt et al. 2015). O’Donnell argues that this gap stems from the transplanting of laws and constitutions to new democracies ("poliarchy's latecomers") and the view that "informal rules trumped formal ones".

2 See however Barr (2001, p. 24) for a different view. Making the case of social over private insurance, he argues that, unlike private insurance companies, public agencies can provide insurance even when there is true uncertainty. 
will not be fully contingent. If outcomes are observable, governments are still able to act ex-post on a discretionary basis. In this interpretation, we borrow from the literature of economics of information and contracts (for surveys see, among others, Macho-Stadler and Pérez Castrillo 2001; Bolton and Dewatripoint 2004; Salanie 2005).

Either way, what is key to our argument is that individuals' utility depends on some circumstances that cannot be contemplated in formal programs, but can be taken into account when the government acts ex-post. These circumstances include things like some health conditions, family circumstances, community quality, etc.

Even if governments lack the institutional capacity required to provide fully contingent protection through formal programs, they can often still protect individuals on a discretionary basis. When the law enforcing institutions are weak, governments can tolerate noncompliance of some costly regulations, providing an implicit discretionary transfer to individuals who have suffered a negative shock. Holland (2016) shows for example that mayors in poor districts of Chile prevent the police from enforcing norms on street vendors, and that politicians in Colombia and Peru reduce enforcement against squatting. These interventions would not be possible under strict enforcement institutions, i.e. under a commitment regime. Also, these interventions meant to benefit street vendors and squatters would not be justifiable in the presence of a sophisticated welfare state. But in the absence of sufficient state capacity, informal social protection can operate as an imperfect substitute for a formal welfare state. Turning a blind eye on these cases of noncompliance requires little if any state capacity. In many developing countries, the political discourse is full of references to "flexibility" and "social sensitivity" when it comes to the justification of this lack of enforcement. In our view, this may not be just rhetoric since many citizens seem to take politicians "flexibility" and "social sensitivity" into account when they decide their vote.

Our highly stylized model is mute regarding the specificities of the "commitment technology", i.e. the set of institutions that provide the government the ability to commit. This is a deliberate modeling choice that, in our view, contributes to make the model general and applicable to a wide range of specific cases ${ }^{3}$. Nevertheless, our preferred interpretation is that the "commitment technology" is provided to a large extent by the law enforcing institutions. A discretionary regime emerges when these institutions are weak. A government -and in particular its executive branch-can turn a blind eye on noncompliance if the judiciary and supervisory agencies are weak and cannot enforce the law.

Assuming a benevolent government, we build a simple framework to analyze the basic components of the policy dilemma we are interested $\mathrm{in}^{4}$.

3 This is also common practice in the literature on time consistency (Persson and Tabellini 2000).

4 Using the fiction of a benevolent government is also useful to make it clear that the issues we are discussing do not arise because of political representation failures (see Dovi 2014, for a thorough discussion of political representation). 
Nevertheless, in the appendix we extend our basic model including a stage in which citizens vote for institutions and policies at the beginning of the game. In this framework, individuals will not support commitment if discretion provides higher expected utility than commitment. The country will thus have weak enforcement capacity but, unlike in most of the literature on informality, in our model weak enforcement capacity is an endogenous outcome conducive to the desired discretionary policy regime. Weak enforcement capacity is not the ultimate cause of lack of enforcement but a choice citizens make to facilitate "flexibility".

This paper is related to several strands of the literature. As Varian (1980), we consider a model in which there is room for social insurance because of incomplete insurance markets. But unlike in Varian's framework, in our model only part of individuals' income can be insured by the government on a precommitted basis.

We borrow ideas from the macroeconomic policy literature that followed the seminal papers of Kydland and Prescott (1977) and Calvo (1978). This literature clarified the pros and cons of commitment and discretion in monetary and fiscal policies (see Persson and Tabellini 1990, 2000, for surveys). We do not see a parallel development in the literature about redistribution, even though the dilemma between discretion and commitment is at least as pressing in this field as in macroeconomics. Lindbeck and Weibull (1988) is a remarkable exception. They argue that the formal welfare states can provide a commitment technology, reducing the distortion caused by discretionary social protection policies.

The idea that governments choose not to fully enforce norms is of course at the heart of the literature on optimal enforcement initiated by Becker (1968). Our contribution is closer in aims and vision to a recent literature that suggests that non enforcement is often a form of informal insurance (Ceni 2014; Loayza and Rigolini 2011; Holland 2014b, 2016). These contributions, including the present paper, are part of a recent literature on politically-motivated lack of enforcement (Brollo et al. 2014; Feierherd, 2017; Casaburi and Troiano 2015; Burgess et al. 2012) $)^{5}$.

Three sections and an appendix follow this introduction. In section 2 we present the basic model with a benevolent government. We describe the economy and solve the model under discretion and commitment. In section 3, we compute utility at the optimum and compare the pros and cons of committing to a simple social protection rule and conducting a discretionary policy. This is what we call the dilemma of formalization. While section 2 is essentially technical, section 3 contains an informal discussion of the results and main intuitions. We summarize

5 In the same spirit, Sandmo (2005) suggests that "It is, e.g., not obvious that the low degree of enforcement of the tax law in some sectors or countries is entirely due to cost considerations; it may also be because the electorate is actually against attempts to achieve a higher rate of compliance. The reasons underlying such resistance may be several, reflecting both judgments of the overall fairness of the tax system and people's self-interest in a lax enforcement policy, either as sellers or buyers of black market services". 
and conclude in section 4 . The appendix contains the proofs of the propositions and a political extension of the basic model that shows why citizens may not support the law enforcement institutions.

\section{THE BASIC MODEL}

\subsection{The setting}

We consider a population of measure one. Even though, for all that matters, the population is homogenous from an ex-ante perspective, for expository convenience, we index individuals with the subindex $i$. For simplicity (and with no loss of generality) we assume that $i$ is continuous in the real numbers and individuals are uniformly distributed according to the unimportant trait $i$ in the $[0,1]$ interval.

Individuals produce and consume a single good exerting effort. The effort is private information. The output each individual produces is observable by everybody, including the government, but only part of it is insurable through formal government programs. The rest of output is not insurable on a pre-committed basis. Formal pre-committed government transfers -and hence government formal insurance- can only be conditioned on the verifiable probabilistic part of output, but ex-post discretionary insurance can be made contingent on both components. We denote by $x_{i}$ and $\varepsilon_{i}$ the components of output that, under commitment, are insurable and non-insurable, respectively. Both components of output take two values, high $(\bar{x}$ and $\bar{\varepsilon})$ and low $(\underline{x}$ and $\underline{\varepsilon})$.

Effort can be high $(H)$ and low $(L<H): a_{i} \in\{H, L\}$. The probabilities of high output conditional on effort are $P_{a_{i}}$ and $q_{a_{i}}$, for the $x$ and $\varepsilon$ components of output, respectively ${ }^{6}$. The probability of high insurable output is increasing in effort $P_{H}>P_{L}$, and of high non-insurable output is non-decreasing in effort $q_{H} \geq q_{L}$. If $q_{H}>q_{L}$, the unconditional distributions of $x_{i}$ and $\varepsilon_{i}$ are not independent, for high effort raises the probability of high output in both components.

Because of government policies, disposable income $\left(w_{i}\right)$ may differ from income before transfers $\left(x_{i}+\varepsilon_{i}\right)$. The government is constrained only by the aggregate resources constraint and a non-negativity constraint on disposable income, so we do not impose any special constraint on the form of the redistributive policies. Nevertheless, the government will have no motive in our setting to treat differently two individuals who got the same output, so we will focus on policies that can be written as mappings from the pairs $\left(x_{i}, \varepsilon_{i}\right)$ to disposable income. The government does not observe effort and therefore cannot condition disposable income on it.

6 For simplicity, we assume that, conditional on $a_{i}$, the insurable and uninsurable components of output are independent: $\operatorname{Prob}\left(x_{i}, \varepsilon_{i} \mid a_{i}\right)=P_{a_{i}} q_{a_{i}}$. 
We consider two policy regimes, discretion and commitment. In a discretionary regime, individuals decide effort at the beginning. Afterwards output is realized and the government redistributes income. Because the government can condition transfers on total output, disposable income in this regime is $w_{i}=w\left(x_{i}, \varepsilon_{i}\right)$. Under commitment, the government chooses disposable income at the beginning and individuals choose the level of effort afterwards. Commitment constraints the government to redistribution schemes that are contingent only on insurable output $w\left(x_{i}\right)$, and hence disposable income is $w_{i}=w\left(x_{i}\right)+\varepsilon_{i}$.

The timeline in Figure 1 describes how events unfold.

While pre-committed policies are implemented through formal programs, discretionary policies are not. The latter are interventions (and omissions in the case of lack of enforcement) that link some outcomes that are non-insurable from an ex-ante perspective to disposable income. By their very nature, discretionary policies represent deviations from formal pre-committed policies. In this sense, when the government chooses discretion, it introduces a gap between de jure and de facto policies.

Individuals' preferences can be represented by an expected utility function increasing and concave in consumption, decreasing in effort and, for simplicity, additively separable in consumption and effort. In our framework, individuals will consume their disposable income, so we can directly write their expected utility in terms of income: $E\left[u\left(w_{i}\right)\right]-a_{i}$.

We assume the government is benevolent and maximizes a social welfare function à la Bentham: $\int_{0}^{1}\left[E\left[u\left(w_{i}\right)\right]-a_{i}\right] d i$. Because individuals are risk averse, the government will provide insurance.

We use backward induction to characterize sub-game perfect equilibria.

FIGURE 1

THE TIMING OF THE GAME

\section{Discretion}

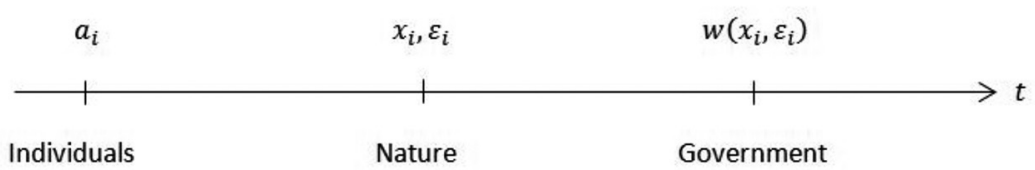

\section{Commitment}

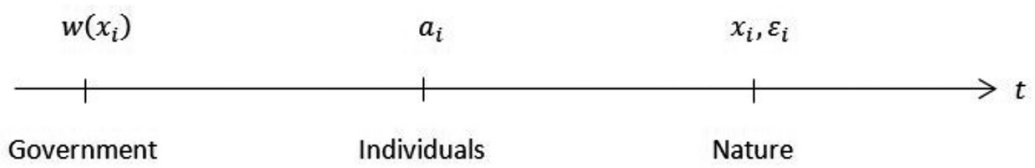




\subsection{Discretion}

The timing in this regime is as follows:

1. Individuals play first, choosing $a_{i}$.

2. Nature chooses $x_{i}$ and $\varepsilon_{i}$, with probabilities $P_{a_{i}}$ and $q_{a_{i}}$.

3. The government chooses $w_{i}$.

Our main result in this section is as follows:

Proposition 1. Under discretion, (i) the government equalizes disposable income $w_{i}=w, \forall i$, and hence provides full insurance on total output, (ii) individuals exert low effort, (iii) average per capita output is low: $w=E[x+\varepsilon]=P_{L} \bar{x}+\left(1-P_{L}\right) \underline{x}+q_{L} \bar{\varepsilon}+\left(1-q_{L}\right) \underline{\varepsilon}$ and (iv) expected individual utility is $u(w)-L$.

The intuition behind this result is straightforward. When the government's turn to play arrives, individuals have already chosen effort. Therefore, under discretion the government will have no incentive concerns and, because it is benevolent, it will equalize disposable income across individuals, providing full insurance. At the beginning, individuals anticipate that there will be full insurance and have no incentives to choose high effort. Therefore, the only equilibrium in this setting is one in which individuals exert low effort, output is low and the government provides full insurance.

In this environment, the government faces a Samaritan's dilemma (Buchanan 1975). Proposition 1 formalizes Buchanan's non-formal statement of this dilemma.

\subsection{Commitment}

Commitment introduces two important changes in the policy game: (i) the timing is reversed, with the government now playing first, and (ii) the government is constrained to condition disposable income on insurable output. Playing first gives the government an advantage, because it is no longer constrained to choosing time consistent policies, but it also brings a cost, for the government cannot condition transfers on anything else than the insurable component of output. So there is a gain in credibility but also a potential loss in flexibility.

The timing is as follows:

1. The government plays first and chooses $w\left(x_{i}\right)$.

2. Individuals play second and choose $a_{i}$.

3. Finally, nature plays and chooses $\left\{x_{i}, \varepsilon_{i}\right\}$, with probabilities $P_{a_{i}}$ and $q_{a_{i}}$.

Recall that, under commitment, $w_{i}=\left(x_{i}\right)+\varepsilon_{i}$, implying that the government cannot provide full insurance, for it will not be able to insure individuals against shocks to $\varepsilon_{i}$. Notice also that this assumption implies that the government is choosing a pair $\underline{w}=w(\underline{x})$ and $\bar{w}=w(\bar{x})$. 
As in the discretionary regime, we solve by backward induction. We start by analyzing individuals' choice and then we analyze the government's problem.

\subsubsection{Individuals' optimization problem}

Individuals maximize their expected utility given the pair $(\underline{w}, \bar{w})$ chosen by the government:

$$
\max _{a_{i} \in\{H, L\}} U\left(a_{i} ; \underline{w}, \bar{w}\right)
$$

where

$$
\begin{aligned}
U\left(a_{i} ; \underline{w}, \bar{w}\right) & =q_{a_{i}}\left[P_{a_{i}} u(\bar{w}+\bar{\varepsilon})+\left(1-P_{a_{i}}\right) u(\underline{w}+\bar{\varepsilon})\right] \\
& +\left(1-q_{a_{i}}\right)\left[P_{a_{i}} u(\bar{w}+\underline{\varepsilon})+\left(1-P_{a_{i}}\right) u(\underline{w}+\underline{\varepsilon})\right]-a_{i}
\end{aligned}
$$

The individuals best response functions can be characterized in terms of a high- and a low-effort region $(H R$ and $L R)$ in the $(\underline{w}, \bar{w})$ space. Formally:

Definition 1. The high-and low-effort regions are the sets of $(\underline{w}, \bar{w})$ such that high and low effort are the individuals' best response to $(\underline{w}, \bar{w})$ :

$$
\begin{aligned}
& H R=\{\underline{w}, \bar{w} \mid U(H ; \underline{w}, \bar{w}) \geq U(L ; \underline{w}, \bar{w})\} \\
& L R=\{\underline{w}, \bar{w} \mid U(H ; \underline{w}, \bar{w})<U(L ; \underline{w}, \bar{w})\}
\end{aligned}
$$

We define the incentives line as the frontier between the high- and the loweffort regions. Formally:

Definition 2. The incentives line (IL) is the set of $(\underline{w}, \bar{w})$ such that individuals are indifferent between high and low effort, i.e.

$$
U(H ; \underline{w}, \bar{w})=U(L ; \underline{w}, \bar{w})
$$

The following proposition establishes some useful properties of the incentives line and the effort regions.

\section{Proposition 2. [The individuals' best responses]}

1. The incentives line (IL) is a continuous single-valued function mapping from $\underline{w}$ to $\bar{w}$.

2. Points to the left of the IL in the $(\underline{w}, \bar{w})$ space belong to the high effort region and points to the right belong to the low effort region.

3. The crossing of the IL and the 45-degree line. 
a. There is no crossing, the IL lies to the left of the 45-degree line, and the 45-

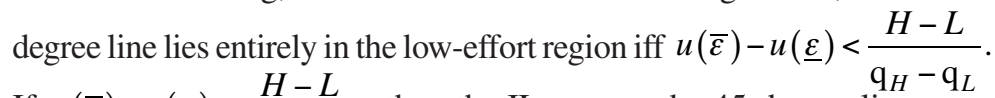

b. If $u(\bar{\varepsilon})-u(\underline{\varepsilon}) \geq \frac{H-L}{\mathrm{q}_{H}-\mathrm{q}_{L}}$, then the IL crosses the 45-degree line once, at the point $\left(w_{c}, w_{c}\right), w_{c} \geq 0$ defined by

$$
u\left(w_{c}+\bar{\varepsilon}\right)-u\left(w_{c}+\underline{\varepsilon}\right)=\frac{H-L}{q_{H}-q_{L}}
$$

c. The slope of the IL at the crossing is smaller than zero or larger than 1 .

d. $w \leq w_{c} \Rightarrow(w, w) \in H R$ and $w>w_{c} \Rightarrow(w, w) \in L R$.

Proposition 2 characterizes the individuals' best response function to government's policy. Notice that, for some parameter values, "full insurance" is compatible with individuals choosing high effort. This is so because "full insurance" in this framework is constrained to insurable output. Even if the government provides full insurance on insurable output, i.e. it chooses $(w, w)$, the non-insurable component of output still provides incentives for high effort if disposable insurable income is not too large: $w \leq w_{c}$. Of course, for this to be feasible, $w_{c}$ must be larger than zero and the proposition establishes the conditions for this to hold.

Figure 2 provides representations of the effort regions. In the left panel, we consider a case in which full insurance induces low effort. In the right panel, we represent an example in which the $I L$ crosses the 45-degree line in the positive quadrant and full insurance is consistent with high effort, provided after-transfer income is not too large.

Since all individuals are alike, aggregate insurable income can be computed as:

$$
\begin{array}{cc}
x_{H}=P_{H} \bar{x}+\left(1-P_{H}\right) \underline{x} & \text { if }(\underline{w}, \bar{w}) \in H R \\
x_{L}=P_{L} \bar{x}+\left(1-P_{L}\right) \underline{x} & \text { if }(\underline{w}, \bar{w}) \in L R
\end{array}
$$

The following corollary to proposition 2 establishes in which effort region policies $\left(x_{H}, x_{H}\right)$ and $\left(x_{L}, x_{L}\right)$ lie. This intermediate result will prove useful for proposition 3 .

Corollary 1. The policy $\left(x_{a}, x_{a}\right) \in H R$ iff $x_{a} \leq w_{c}$, where $a \in\{H, L\}$.

Corollary 1 follows directly from proposition 2 , item $3(\mathrm{~d})$.

\subsubsection{The government's problem}

The benevolent government maximizes a social welfare function $\grave{a}$ la Bentham, subject to the economy resources constraint and to the individuals' incentive 
FIGURE 2

THE EFFORT REGIONS

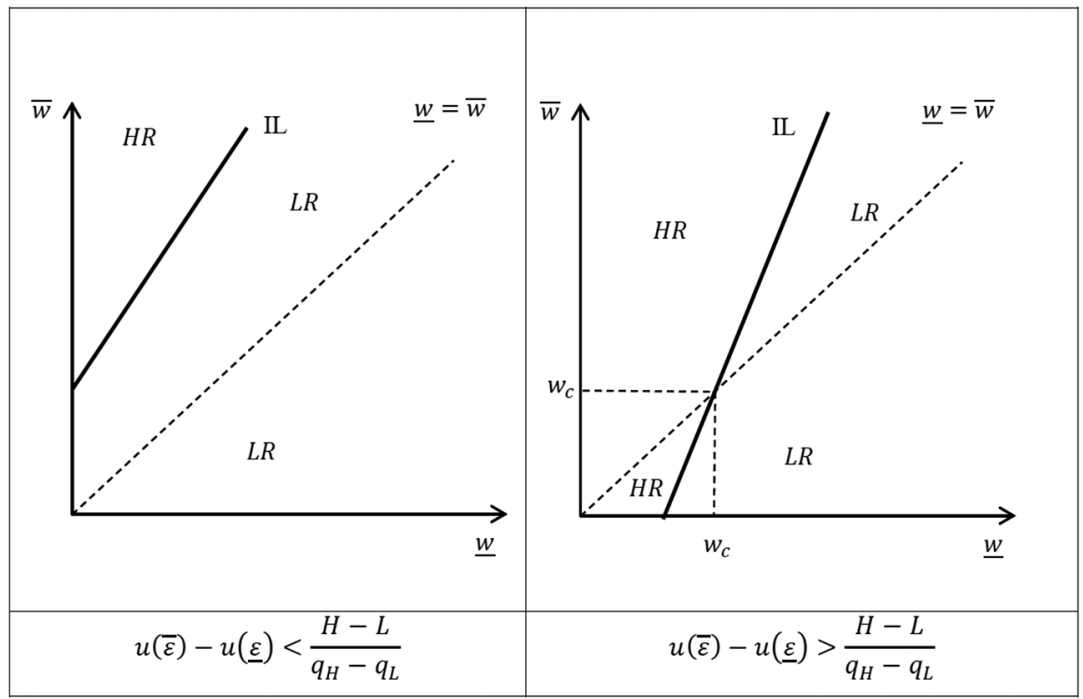

compatibility constraints. Under commitment, the government is unable to condition transfer policies on $\varepsilon$ and can only make transfers contingent on $x$, so it will directly choose a pair $(\underline{w}, \bar{w})$ and, indirectly, the effort levels $a_{i}$.

$$
\begin{aligned}
\sup _{\underline{w}, \bar{w}, a_{i}} & \int_{0}^{1} U\left(a_{i} ; \underline{w}, \bar{w}\right) d i \\
\text { s.t. }: & \int_{0}^{1}\left[P_{a_{i}}(\bar{x}-\bar{w})+\left(1-P_{a_{i}}\right)(\underline{x}-\underline{w})\right] d i \geq 0 \\
& a_{i}=\underset{a}{\operatorname{argmax}} U(a ; \underline{w}, \bar{w}) \forall i
\end{aligned}
$$

Notice that even though the government is benevolent, the incentive compatibility constraints are needed, since the government cannot command individuals' effort.

This program is not "well behaved" in the sense that neither the option set nor the indifference curves are necessarily convex.

The government budget set is convex if and only if the no insurance point $(\underline{x}=\bar{x})$ happens to lie exactly on the incentives line. Note first that the government budget constraint, which is at the frontier of the budget set, always include the no insurance point. No matter what level of effort individuals choose, the government can always choose not to redistribute income: $\underline{w}=\underline{x}$ and $\bar{w}=\bar{x}$. So the government budget constraint in the $(\underline{w}, \bar{w})$ space, necessarily passes through the point $(\underline{x}, \bar{x})$. 
In turn, within an effort region, the budget constraint is a straight line with slope:

$$
\left.\frac{d \bar{w}}{d \underline{w}}\right|_{R C}=-\frac{1-P_{a_{i}}}{P_{a_{i}}}<0
$$

Hence, the slope of the budget constraint is discontinuous at the crossing with the IL. Furthermore, the budget constraint presents a discontinuity also in level, unless the no insurance point lies exactly on the incentives line.

The government option set in each effort region is the area delimited by the axis, the incentives compatibility line (IL) and the corresponding branch of the resources constraint ${ }^{7}$.

We present two examples in Figure 3. The shaded areas represent the government budget sets. In the left panel, we represent a case in which high effort is compatible with full insurance in insurable output. In this case, because of the incentives provided by the uninsurable component of output, the government can provide full insurance in insurable output and yet citizens choose high effort. In the right panel, the government cannot simultaneously provide full insurance in insurable output and induce individuals to choose high effort. In this second example, parameter values are such that the government induces low effort if it chooses full insurance in insurable output.

FIGURE 3

THE GOVERNMENT BUDGET SETS

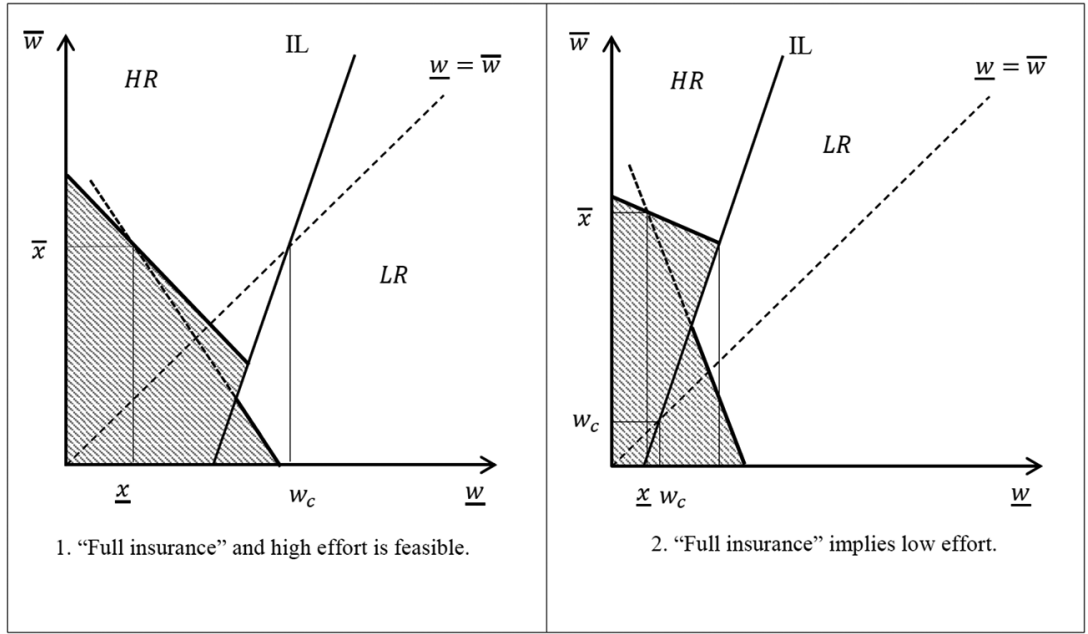

$7 \quad$ The government conditional option set is closed in $H R$ and open in $L R$, because IL belongs to $H R$. 
The slope of citizens' indifference curves is discontinuous at the crossing with the incentives line. Indeed, the slope of the indifference curves is:

$$
\left.\frac{d \bar{w}}{d \underline{w}}\right|_{U}=-\frac{1-P_{a_{i}}}{P_{a_{i}}}\left(\frac{q_{a_{i}} u^{\prime}(\underline{w}+\bar{\varepsilon})+\left(1-q_{a_{i}}\right) u^{\prime}(\underline{w}+\underline{\varepsilon})}{q_{a_{i}} u^{\prime}(\bar{w}+\bar{\varepsilon})+\left(1-q_{a_{i}}\right) u^{\prime}(\bar{w}+\underline{\varepsilon})}\right)<0
$$

where the negative sign follows from (i) $u^{\prime}()>$.0 and (ii) $P_{a_{i}}, q_{a_{i}} \in[0,1]$. At the IL, an infinitesimal increase in $\underline{w}$ causes a discrete drop in $P_{a_{i}}$ and an infinitesimal decrease in the expected marginal utility of income in the bad state, causing a discrete increase in the slope of the indifference curves (in absolute terms). In other words, in a neighborhood of the IL, the indifference curves are steeper to the right than to the left of the IL because $P_{L}<P_{H}$.

The indifference curves are flatter than the resources constraint to the right of the 45-degree line, tangent to the resources constraint on the 45-degree line, and steeper than the resources constraint to the left of the 45-degree line:

$$
\left.\left.\frac{d \bar{w}}{d \underline{w}}\right|_{U} \gtreqless \frac{d \bar{w}}{d \underline{w}}\right|_{R C} \text { if } \underline{w} \gtreqless \bar{w}
$$

Equation (8) follows from equations (6) and (7) and the following observations: (i) $0<u^{\prime}\left(\right.$.), (ii) $q_{a_{i}} \in[0,1]$ and iii) $u^{\prime}(\underline{w}+\varepsilon) \lesseqgtr u^{\prime}(\bar{w}+\varepsilon)$ if $\underline{w} \gtreqless \bar{w}, \varepsilon \in\{\underline{\varepsilon}, \bar{\varepsilon}\}$.

We present an example of several indifference curves in Figure 4.

FIGURE 4

THE INDIFFERENCE CURVES

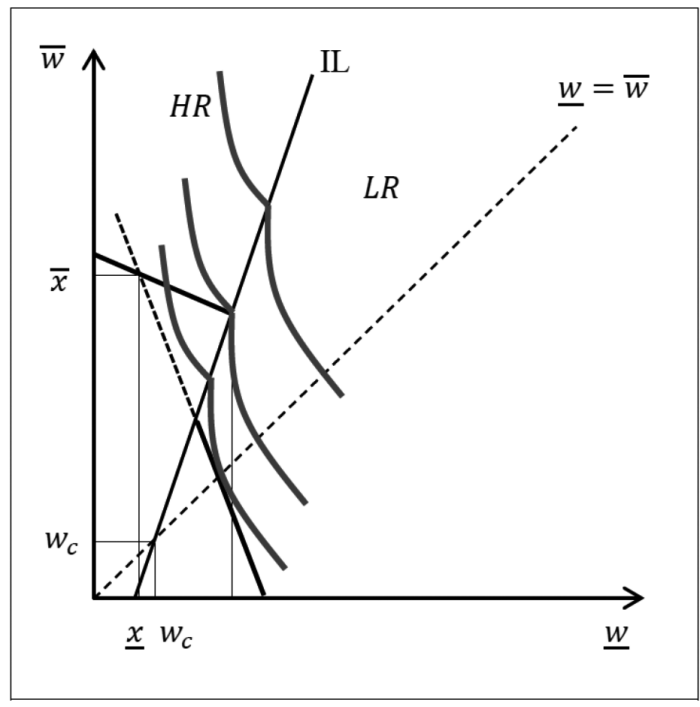


We circumvent the non-convexity issues solving the government program in two steps. In the first step we characterize the optimal policies conditional on the level of effort, i.e. we identify the optimum pair $(\underline{w}, \bar{w})$ in each effort region $^{8}$. In the second step we choose the best of these two policies.

Our main results in this section are summarized in proposition 3.

Proposition 3. Under commitment, the model exhibits the following equilibria:

1. Full insurance (on insurable output) high effort equilibrium, where the optimal policy is $\left(x_{H}, x_{H}\right)$ and individuals choose $a_{i}=H$. This equilibrium exists and is unique if and only if $\left(x_{H}, x_{H}\right) \in H R\left(\Leftrightarrow x_{H} \leq w_{c}\right)$.

2. Incomplete insurance high effort equilibrium, where the government optimal policy is the pair $\left(\underline{w}_{H}, \bar{w}_{H}\right), \underline{w}_{H}<\bar{w}_{H}$, and $a_{i}=H$. The policy $\left(\underline{w}_{H}, \bar{w}_{H}\right)$ is determined by the following two conditions: (i) $P_{H}\left(\bar{x}-\bar{w}_{H}\right)+\left(1-P_{H}\right)\left(\underline{x}-\underline{w}_{H}\right)=0$ and (ii) $U\left(L, \underline{w}_{H}, \bar{w}_{H}\right)=U\left(H, \underline{w}_{H}, \bar{w}_{H}\right)$. If two or more points satisfy conditions $(i)$ and (ii), the equilibrium will take place at the one with largest $\underline{w}$, if $\underline{w}<\bar{w}$, and with smallest $\underline{w}$ if $\underline{w}>\bar{w}$. This equilibrium exists iff

a. $\left(x_{H}, x_{H}\right) \in L R\left(\Leftrightarrow x_{H}>w_{c}\right),\left(x_{L}, x_{L}\right) \in L R\left(\Leftrightarrow x_{L}>w_{c}\right)$ and $U\left(L, x_{L}, x_{L}\right) \leq U\left(H, \underline{w}_{H}, \bar{w}_{H}\right) ;$ or

b. $\left(x_{H}, x_{H}\right) \in L R\left(\Leftrightarrow x_{H}>w_{c}\right)$ and $\left(x_{L}, x_{L}\right) \in H R\left(\Leftrightarrow x_{L}>w_{c}\right)$.

3. Full insurance (on insurable output) low effort equilibrium, where the optimal policy is $\left(x_{L}, x_{L}\right)$ and $a_{i}=L$. This equilibrium exists and is unique if and only if $\left(x_{H}, x_{H}\right) \in L R\left(\Leftrightarrow x_{H}>w_{c}\right),\left(x_{L}, x_{L}\right) \in L R\left(\Leftrightarrow x_{L}>w_{c}\right)$ and $U\left(L, x_{L}, x_{L}\right)>U\left(H, \underline{w}_{H}, \bar{w}_{H}\right)$.

We present in Figure 5 a graphical representation of some equilibria. The examples in the figure do not exhaust the possibilities, but we have drawn one example for each type of equilibrium characterized in proposition 3 , so we hope they are sufficiently illustrative.

Panel 1 in Figure 5 is an example of a full insurance and high effort equilibrium. The incentives line crosses the 45-degree line at $\left(w_{c}, w_{c}\right)$ with $w_{c}>x_{H}$, and hence $\left(x_{H}, x_{H}\right)$ lies in $H R$. The indifference curve farthest from the origin that the government can achieve conditional on high effort is tangent to the resources constraint at the crossing with the 45-degree line. Hence $\left(x_{H}, x_{H}\right)$ is the best the government can do in the high-effort region. In the low-effort region, the best the government can do is to choose $\left(\underline{w}_{L}, \bar{w}_{L}\right)$, since the indifference curves are flatter than the resources constraint to the right of the 45-degree line. The indifference curve that passes through $\left(x_{H}, x_{H}\right)$ lies farthest from the origin than the one that

8 In the government program we use the supremum rather than the maximum because the government option set in the low-effort region is open, because we have made the assumption that individuals choose high effort when they are strictly indifferent between the two effort levels. 


\section{FIGURE 5}

\section{THE SET OF EQUILIBRIA UNDER COMMITMENT}

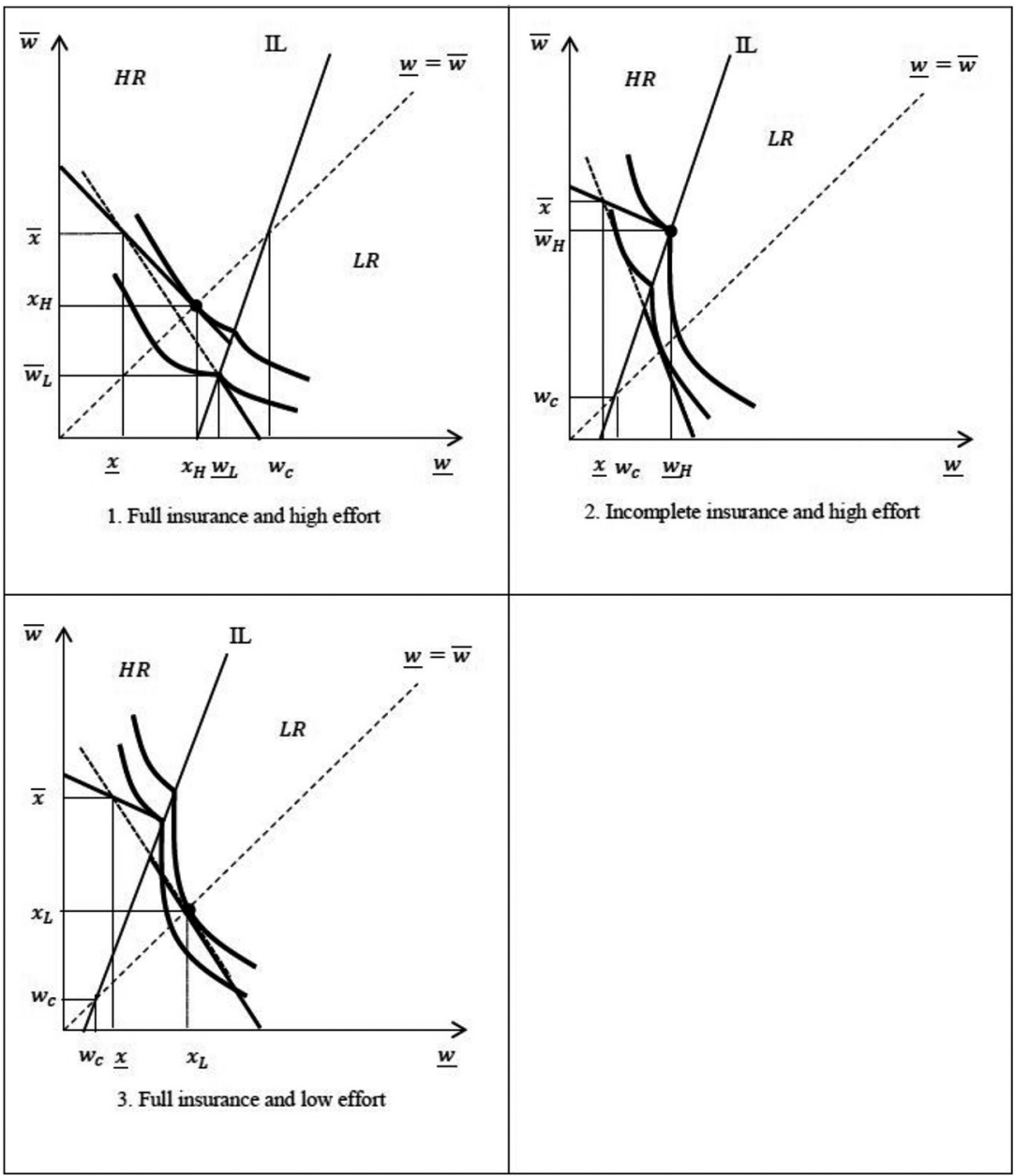

passes through $\left(\underline{w}_{L}, \bar{w}_{L}\right)$, which implies that the optimum in the high effort region dominates the optimum in the low effort region and is thus the global optimum.

Panel 2 in Figure 5 presents an example of an incomplete insurance and high effort equilibrium. For this configuration of parameters, $w_{c}<x_{L}<x_{H}$ and hence $\left(x_{H}, x_{H}\right) \notin H R$, implying that the best the government can do if it wants to induce high effort is to provide incomplete insurance at point $\left(\underline{w}_{H}, \bar{w}_{H}\right)$. In the low effort region, the government can implement full insurance since $\left(x_{L}, x_{L}\right) \in L R$, and this is the best policy in this region. In the example represented in this panel, the HR-optimum is preferred to the LR-optimum and is thus the global optimum. More generally, either of these constrained optimums can be the global 
optimum, depending on parameter values. Indeed, the low-effort optimum has the benefit of lower effort and higher insurance than the high-effort optimum, but at the cost of lower average income. In this example, we have assumed that the average income effect dominates the insurance and effort effects, and hence the global optimum involves incomplete insurance and high effort.

Panel 3 in Figure 5 represents an example of a full insurance and low effort equilibrium. It is very similar to the example in panel 2 , save for the fact that the insurance and effort effects dominate the average income effect and therefore the constrained low-effort optimum is the global optimum. This could happen, for instance, if individuals are more risk averse, experience higher disutility of effort or the impact of effort on the probability of high output is smaller than in the previous example.

\section{THE DILEMMA OF FORMALIZATION}

A government that can abandon discretion to embrace formal pre-committed social protection policies may face a non-trivial choice if fully contingent rules are not possible. To clarify the relevant tradeoffs, we compare utility in equilibrium under discretion and commitment.

We show in proposition 4 that the welfare net gains from formalization can be decomposed in three additive terms, namely (i) the welfare gains due to the increase in expected income, (ii) the welfare losses due to higher risk, and (iii) the welfare losses due to higher effort.

Proposition 4. The welfare gains from formalization can be decomposed in three terms:

$$
G=\left(u\left(x_{a}+\varepsilon_{a}\right)-u\left(x_{L}+\varepsilon_{L}\right)+\left[E[u(w+\varepsilon) \mid a]-u\left(x_{a}+\varepsilon_{a}\right)\right]-(a-L)\right.
$$

where a is effort, $x_{a}$ is defined in equations (4) and (5), $\varepsilon_{a}=q_{a} \bar{\varepsilon}+\left(1-q_{a}\right) \underline{\varepsilon}$ and $w \in\{\underline{w}, \bar{w}\}$ is the government policy in a commitment equilibrium, and

1. $u\left(x_{a}+\varepsilon_{a}\right)-u\left(x_{L}+\varepsilon_{L}\right) \geq 0$ are the welfare gains due to the increase in expected income;

2. $\left[E[u(w+\varepsilon) \mid a]-u\left(x_{a}+\varepsilon_{a}\right)\right]<0$ are the welfare losses due to higher risk; and

3. $-(a-L) \leq 0$ are the welfare losses due to higher effort.

The first term captures the potential utility gains that arise if formalization induces high effort and raises expected income. Under discretion, individuals choose low effort because the government provides full insurance. Under commitment, the government provides partial insurance which, depending on parameter values, may induce individuals to exert high effort. If this is the case, formalization brings about an increase in expected income. 
The second term is the welfare loss from formalization that arises because in a commitment equilibrium individuals face higher income risk than in the discretionary equilibrium. Notice that even if the commitment equilibrium involves full insurance in insurable output, commitment brings about higher risk than discretion because of the uninsurable component of income.

The third term is the cost of higher effort. It is the counterpart of the first effect and it arises if and only if formalization induces more effort and higher income.

It is immediately clear from the above that discretion is preferred to commitment if the commitment equilibrium involves low effort. There are no benefits from formalization in this case, since expected income does not increase, and there are costs, because the government loses its capacity to provide insurance on a discretionary basis. But discretion may be preferred to commitment even if commitment induces high effort. Indeed, if the welfare losses stemming from higher risk and effort outweigh the welfare gains from higher expected income, discretion is still preferred to commitment.

In turn, commitment is (weakly) preferred to discretion if all income is insurable (i.e. if $\underline{\varepsilon}=\bar{\varepsilon}=0$ ). In this case, the government can replicate the discretionary policy under commitment, so the outcome cannot be strictly better off under discretion than under commitment ${ }^{9}$. Therefore, the existence of uninsurable income is a necessary condition for discretion to dominate commitment.

This does not mean, however, that discretion is necessarily preferred to commitment when the state capacity is so low that all income is uninsurable. In this extreme case the government provides no insurance at all under commitment $(\underline{x}=\bar{x}=\underline{w}=\bar{w}=0)$, and full insurance under discretion. If the incentive distortions associated to full insurance are large enough, commitment may be preferred to discretion, even when it involves no insurance.

These results imply that in our model uninsurable income undermines the incentives that benevolent governments have to "formalize" social policies. The lower the state capacity to provide formal insurance on a pre-committed basis, the higher the incentives a benevolent government has to adopt a discretionary policy. Hence, the model provides a simple story to explain why informality is so widespread in developing countries.

Our model is of course not meant to be taken literally, but a parable of the basic tradeoff involved in the design of institutions of commitment when the state capacity to provide insurance on a pre-committed basis is limited. In the real world, neither private firms nor the government can provide formal insurance against all shocks, but governments often have more leeway to provide ex-post informal insurance against at least some shocks. In our model, uninsurable income represents any shock that neither private companies nor the government can formally insure citizens against.

9 Indeed, in the absence of uninsurable income, equation (9) implies that the welfare gains from formalization are zero if the government chooses $\underline{w}=\bar{w}=x_{L}$. Hence $G \geq 0$ if there is no uninsurable income. 
Holland (2016) provides some vivid examples from Chile, Colombia and Peru in which politicians tolerate noncompliance of norms on street vendors and squatting. Street vendors and squatters are poor people who most likely had few opportunities in life (most of them were born in the "wrong" neighborhood). Similarly, tolerance of smuggling has been advocated as an informal substitute for weak formal social policies ${ }^{10}$. In these cases, tolerance of noncompliance involves some implicit redistribution in favor of the beneficiaries. In terms of our model, these individuals received a negative realization of the uninsurable shock when they were born or early in life.

\section{Summary and CONClusions}

We present a model aimed at explaining why governments often seem to redistribute income on a discretionary basis. Unable to commit to sophisticated fully contingent rules, governments may find it optimal to avoid commitment to simple rules and choose discretion in order to gain flexibility.

Incorporating a non-insurable component of output, we provide a simple representation of the idea that governments may not be able to condition formal social protection policies on all utility relevant outcomes. Because of this, governments cannot commit to fully contingent policies and are constrained in the amount of insurance they can provide on a pre-committed basis. We call these partially-contingent pre-committed policies simple rules.

The discretionary social protection regime described in this paper could be thought of as a stylized representation of a wide range of real world policies, including tolerance of noncompliance and informality, soft-budgeting and protection of decadent industries. In this perspective, several policies that have been traditionally thought of as the result of government inability to enforce the law could be given a different rationale.

Weak state capacities are crucial for our results. Nevertheless, it is not the weak enforcement capacity that drives the results but the limited capacity to implement sufficiently sophisticated redistributive policies on a pre-committed basis. In our model, weak enforcement is an endogenous outcome that serves the purpose of gaining "flexibility". The real challenge is to strengthen state capacities in ways that make it possible to commit to sufficiently sophisticated transfer policies so that the informal welfare state can be phased out, giving place to more formal policies.

10 In Uruguay, a member of a social movement supported by the Social Development Ministry argues in a blog that "Informality is the way of living of inhabitants of the frontier. (...) Smuggling is a bad word in the South; here it means jobs" (authors translation from http:// elmuertoquehabla.blogspot.com/2012/02/camino-de-los-quileros.html). 


\section{BibLIOGRAPHY}

Barr, N. (2001). The Welfare State as Piggy Bank. Oxford University Press. Becker, G. (1968). "Crime and Punishment: An Economic Approach", Journal of Political Economy, Vol. 76; 169-217.

Bolton, P. and M. Dewatripoint (2004). Contract Theory. The MIT Press.

Brollo, F., K. Kaufmann, and E. La Ferrara (2014). The Political Economy of the Enforcement of Conditional Welfare Programs: Evidence from Brazil. Bocconi University and IGIER, University of Warwick and CAGE.

Buchanan, J. (1975). "The Samaritan's Dilemma". In: Altruism, Morality, and Economic Theory. Ed. by Edmund S. Phelps. New York: Russell Sage Foundation, 71-86.

Burgess, R., M. Hansen, B. Olken, P. Potapov, and S. Sieber (2012). "The Political Economy of Deforestation in the Tropics", The Quarterly Journal of Economics, Vol. 127.4; 1707-1754.

Calvo, G. (1978). "On the Time Consistency of Optimal Policy in a Monetary Economy”, Econometrica, Vol. 46.6; 1411-1428.

Casaburi, L. and U. Troiano (2015). "Ghost-House Busters: the Electoral Response to a Large Anti Tax Evasion Program", The Quarterly Journal of Economics, Vol. 131.1; 273-314.

Ceni, R. (2014). "Informality and Government Enforcement in Latin America". Instituto de Economía, FCEA-UDELAR.

Dovi, S. (2014). "Political Representation". In: The Stanford Encyclopedia of Philosophy. Ed. by Edward N. Zalta. Spring 2014.

Downs, A. (1957). An Economic Theory of Democracy. New York: Harper and Row.

Feierherd, G. (2017). "Does the Left Breed Economic Informality? Party Strategies and Selective Enforcement in Brazil". Yale University.

Feld, L. and S. Voigt (2003). "Economic growth and judicial independence: cross-country evidence using a new set of indicators", European Journal of Political Economy, Vol. 19.3; 497-527.

Foldvari, P. (2015). "De Facto Versus de Jure Political Institutions in the Long-Run: A Multivariate Analysis, 1820-2000", Social Indicators Research, 1-19.

Holland, A. (2014a). "Forbearance: Theory and Measurement in the Study of Enforcement Politics", American Journal of Political Science, Vol. 59.2; 357-371.

Holland, A. (2014b). "The Distributive Politics of Enforcement", American Journal of Political Science, Vol. 59.2; 357-371.

Holland, A. (2016). "Forbearance”, American Political Science Review, Vol. 110.2; 232-246.

Knight, F. (1921). Risk, Uncertainty, and Profit. Boston, MA: Hart, Schaffner \& Marx; Houghton Mifflin Co.

Kydland, F. and E. Prescott (1977). "Rules Rather than Discretion: The Inconsistency of Optimal Plans", Journal of Political Economy, Vol. 85.3; 473-492. 
Lindbeck, A. and J. Weibull (1988). "Altruism and Time Consistency: the Economics of Fait Accompli”, Journal of Political Economy, Vol. 96.6; 1165-1182.

Loayza, N. and J. Rigolini (2011). "Informal Employment: Safety Net or Growth Engine?", World Development, Vol. 39.9; 1503-1515.

Macho-Stadler, I. and D. Pérez-Castrillo (2001). An Introduction to the Economics of Information: Incentives and Contracts. Oxford University Press.

Mainwaring, S. and C. Welna (2003). Democratic Accountability in Latin America. Oxford University Press.

O’Donnell, G. (1998). "Horizontal Accountability in New Democracies", Journal of Democracy, Vol. 9.3; 112-126.

Persson, T. and G. Tabellini (1990). Macroeconomic Policy, Credibility and Politics. Harwood Economic Publishers.

Persson, T. and G. Tabellini (2000). Political Economics. Explaining Economic Policy. MIT Press.

Salanie, B. (2005). The Economics of Contracts. The MIT Press.

Sandmo, A. (2005). "The Theory of Tax Evasion: A Retrospective View", National Tax Journal, Vol. LVIII.4; 643-663.

Van de Walle, N. (2001). African Economies and the Politics of Permanent Crisis, 1979-1999. Cambridge University Press.

Varian, H. (1980). "Redistributive Taxation as Social Insurance", Journal of Public Economics, Vol. 14; 49-68.

Voigt, S., J. Gutmann, and L. Feld (2015). "Economic Growth and Judicial Independence, a Dozen Years On: Cross-Country Evidence Using an Updated Set of Indicators", European Journal of Political Economy, Vol. 38; 197-211. 


\section{ApPendix}

\subsection{Discretion}

Proof of Proposition 1. Solving by backward induction, we begin by the government problem. At this stage, individuals' effort is a given and all the uncertainty has been revealed so the benevolent government solves the following program:

$$
\begin{gathered}
\max _{\left\{w_{i}\right\}} \int_{0}^{1}\left[u\left(w_{i}\right)-a_{i}\right] d i \\
s t: \int_{0}^{1} w_{i} d i \leq \int_{0}^{1}\left[P_{a_{i}} \bar{x}+\left(1-P_{a_{i}}\right) \underline{x}+q_{a_{i}} \bar{\varepsilon}+\left(1-q_{a_{i}}\right) \underline{\varepsilon}\right] d i
\end{gathered}
$$

It follows from the first order conditions that the government will equalize disposable income, irrespective of individuals output: $w_{i}=w, \forall i$.

At the beginning, individuals maximize utility knowing that the government will provide full insurance, so individual $i$ solves:

$$
\max _{a_{i}} u(w)-a_{i}
$$

Disposable income equals expected average output, which only marginally depends on individual $i$ action, so he chooses minimum effort: $a_{i}=L$.

Using these results in the resources constraint:

$$
w=P_{L} \bar{x}+\left(1-P_{L}\right) \underline{x}+q_{L} \bar{\varepsilon}+\left(1-q_{L}\right) \underline{\varepsilon}
$$

Expected individual welfare in equilibrium under discretion is thus: $u(w)-L$

QED

\subsection{Commitment}

\subsubsection{The individuals' maximization problem}

Proof of Proposition 2.

1. The incentives line (IL) is a continuous single-valued function mapping from $\bar{w}$ to $\underline{w}$.

By virtue of the implicit function theorem, equation (2) defines a continuous function mapping from $\bar{w}$ to $\underline{w}$ if $\frac{\partial U}{\partial \underline{w}}(H ; \underline{w}, \bar{w})-\frac{\partial U}{\partial \underline{w}}(L ; \underline{w}, \bar{w}) \neq 0$. This
condition is globally fulfilled since:

$$
\begin{gathered}
\frac{\partial U}{\partial \underline{w}}(H ; \underline{w}, \bar{w})-\frac{\partial U}{\partial \underline{w}}(L ; \underline{w}, \bar{w})=\left(1-P_{H}\right)\left(q_{H} u^{\prime}(\underline{w}+\bar{\varepsilon})+\left(1-q_{H}\right) u^{\prime}(\underline{w}+\underline{\varepsilon})\right)- \\
\left(1-P_{L}\right)\left(q_{L} u^{\prime}(\underline{w}+\bar{\varepsilon})+\left(1-q_{L}\right) u^{\prime}(\underline{w}+\underline{\varepsilon})\right)<0
\end{gathered}
$$


The inequality (10) stems from the following observations:

(i) $u^{\prime}(\underline{w}+\bar{\varepsilon})<u^{\prime}(\underline{w}+\underline{\varepsilon})$;

(ii) $q_{H} \geq q_{L}$; $\Rightarrow q_{H} u^{\prime}(\underline{w}+\bar{\varepsilon})+\left(1-q_{H}\right) u^{\prime}(\underline{w}+\underline{\varepsilon}) \leq q_{L} u^{\prime}(\underline{w}+\bar{\varepsilon})+\left(1-q_{L}\right) u^{\prime}(\underline{w}+\underline{\varepsilon}) ;$

(iii) $P_{H}>P_{L} \Rightarrow 1-P_{H}<1-P_{L}$.

2. Points to the left (right) of the IL lie in $H R(L R)$.

This result follows immediately from inequality (10) and the fact that the IL is a continuous function mapping from $\bar{w}$ to $\underline{w}$.

3. Crossing of the IL and the 45-degree line.

(a) There is no crossing, the IL lies to the left of the 45-degree line and the 45degree line lies entirely in the low-effort region iff $u(\bar{\varepsilon})-u(\underline{\varepsilon})<\frac{H-L}{q_{H}-q_{L}}$.
The 45-degree line lies entirely in $L R$ iff

$$
U(H, w, w)<U(L, w, w) \Leftrightarrow u(w+\bar{\varepsilon})-u(w+\underline{\varepsilon})<\frac{H-L}{q_{H}-q_{L}}, \forall w>0
$$

Notice that: (i) $u^{\prime}(w+\bar{\varepsilon})-u^{\prime}(w+\underline{\varepsilon})<0$; (ii) $\lim _{w \rightarrow \infty} u(w+\bar{\varepsilon})-u(w+\underline{\varepsilon})=0$; and (iii) $u(w+\bar{\varepsilon})-u(w+\underline{\varepsilon})$ is continuous. Therefore, iff $u(\bar{\varepsilon})-u(\underline{\varepsilon})<$ $(H-L) /\left(q_{H}-q_{L}\right)$ inequality (11) holds.

(b) If $u(\bar{\varepsilon})-u(\underline{\varepsilon}) \geq \frac{H-L}{q_{H}-q_{L}}$, then the IL crosses the 45-degree line once.

Observations (i) to (iii) in point 1 of this proof imply that iff $u(\bar{\varepsilon})-u(\underline{\varepsilon}) \geq \frac{H-L}{q_{H}-q_{L}}$, the IL intersects the 45-degree line once and only once and equation (2) implies that the crossing takes place at $\left(w_{c}, w_{c}\right)$, $w_{c} \geq 0$, defined by equation (3).

(c) The slope of the IL at the crossing is smaller than zero or larger than 1 . We totally differentiate equation (2) to compute the slope of the IL:

$$
\left.\frac{d \bar{w}}{d \underline{w}}\right|_{I L}=\frac{\frac{\partial U}{\partial \underline{w}}(L ; \underline{w}, \bar{w})-\frac{\partial U}{\partial \underline{w}}(H ; \underline{w}, \bar{w})}{\frac{\partial \bar{w}}{\partial \bar{w}}(H ; \underline{w}, \bar{w})-\frac{\partial U}{\partial \bar{w}}(L ; \underline{w}, \bar{w})}=\frac{A u^{\prime}(\underline{w}+\bar{\varepsilon})+B u^{\prime}(\underline{w}+\underline{\varepsilon})}{C u^{\prime}(\bar{w}+\bar{\varepsilon})+D u^{\prime}(\bar{w}+\underline{\varepsilon})}
$$

where:

$$
\begin{aligned}
& A=q_{L}\left(1-P_{L}\right)-q_{H}\left(1-P_{H}\right) \\
& B=\left(1-q_{L}\right)\left(1-P_{L}\right)-\left(1-q_{H}\right)\left(1-P_{H}\right) \\
& C=q_{H} P_{H}-q_{L} P_{L} \\
& D=\left(1-q_{H}\right) P_{H}-\left(1-q_{L}\right) P_{L}
\end{aligned}
$$


Inequality (10) implies that the numerator in (12) is positive. The denominator can be positive, zero or negative, depending on parameter values. Hence, for the slope of IL to be positive, the denominator must be positive.

Rearranging terms and evaluating equation (12) at the crossing of IL and the 45-degree line (i.e. at $w_{c}=\underline{w}=\bar{w}$ ):

$$
\left.\frac{d \bar{w}}{d \underline{w}}\right|_{I L}=1+\frac{\left(q_{H}-q_{L}\right)\left(u^{\prime}\left(w_{c}+\underline{\varepsilon}\right)-u^{\prime}\left(w_{c}+\bar{\varepsilon}\right)\right)}{C u^{\prime}\left(w_{c}+\bar{\varepsilon}\right)+D u^{\prime}\left(w_{c}+\underline{\varepsilon}\right)}
$$

It is immediately obvious that $\left(q_{H}-q_{L}\right)\left(u^{\prime}\left(w_{c}+\underline{\varepsilon}\right)-u^{\prime}\left(w_{c}+\bar{\varepsilon}\right)\right)>0$ and hence if $C u^{\prime}\left(w_{c}+\bar{\varepsilon}\right)+D u^{\prime}\left(w_{c}+\underline{\varepsilon}\right)>0 \Rightarrow \frac{d \bar{w}}{d \underline{w}_{I L}}>1$.

(d) $w \leq w_{c} \Rightarrow(w, w) \in H R$ and $w>w_{c} \Rightarrow(w, w) \in L R$.

This result follows immediately from previous points in this proposition. Item 3(b) establishes that there is one and only one $w_{c} \geq 0$ at which the IL crosses the 45-degree line if $u(\bar{\varepsilon})-u(\underline{\varepsilon}) \geq \frac{H-L}{q_{H}-q_{L}}$. Points 1,2 and 3(c) imply that $w \leq w_{c} \Rightarrow(w, w) \in H R$ and $w>w_{c} \Rightarrow(w, w) \in L R$.

QED

Remark 1: The fact that, for some parameter values, IL has a negative slope is probably counterintuitive. It implies that, starting at an indifference point, an infinitesimal increase in disposable income in the good state of nature may reduce the incentives for high effort. An increase in $\bar{w}$ has a direct and an indirect effect on incentives that go in opposite directions. The direct effect increases the incentives for high effort: other things equal, the marginal utility of $\bar{w}$ is higher if individuals choose high effort because $P_{H}>P_{L}$. But there is also an indirect effect because the probability of high non-insurable income is also higher with high than with low effort, which implies that the marginal utility of disposable income is lower with high than with low effort. If the indirect effect outweighs the direct effect, an increase in $\bar{w}$ will reduce the incentives for high effort. This does not happen with disposable income in the bad state of nature, because in this case both effects go in the same direction.

\subsubsection{The government's program under commitment}

Proof of Proposition 3.

\section{First step. Optimal policies conditional on effort.}

Let $a^{-} \in\{H, L\}$ denote the effort opposite to $a$, i.e. $a=H \rightarrow a^{-}=L$ and viceversa. Then the government optimization program conditional on effort $a$ can be written as: 


$$
\begin{gathered}
\sup _{\underline{w}, \bar{w}}(a ; \underline{w}, \bar{w}) \\
\text { s.t. }: P_{a}(\bar{x}-\bar{w})+\left(1-P_{a}\right)(\underline{x}-\underline{w}) \geq 0 \\
U(a ; \underline{w}, \bar{w}) \geq U\left(a^{-} ; \underline{w}, \bar{w}\right)
\end{gathered}
$$

Where we have used that all individuals are alike, all choose effort $a$ and there is a mass one of individuals.

The first order conditions are as follows:

$$
\begin{gathered}
\frac{\partial U}{\partial \underline{w}}(a ; \underline{w}, \bar{w})-\lambda\left(1-P_{a}\right)+\mu\left[\frac{\partial U}{\partial \underline{w}}(a ; \underline{w}, \bar{w})-\frac{\partial U}{\partial \underline{w}}\left(a^{-} ; \underline{w}, \bar{w}\right)\right]=0 \\
\frac{\partial U}{\partial \bar{w}}(a ; \underline{w}, \bar{w})-\lambda P_{a}+\mu\left[\frac{\partial U}{\partial \bar{w}}(a ; \underline{w}, \bar{w})-\frac{\partial U}{\partial \bar{w}}\left(a^{-} ; \underline{w}, \bar{w}\right)\right]=0 \\
P_{a}(\bar{x}-\bar{w})+\left(1-P_{a}\right)(\underline{x}-\underline{w})=0 \\
\mu\left[U(a ; \underline{w}, \bar{w})-U\left(a^{-} ; \underline{w}, \bar{w}\right)\right]=0 ; \mu \geq 0 ; U(a ; \underline{w}, \bar{w})-U\left(a^{-} ; \underline{w}, \bar{w}\right) \geq 0
\end{gathered}
$$

For the sake of brevity, we have imposed equality on the resources constraint, because we already know that it must be binding in an optimum. The ICC does not need to be binding, so we consider the Kuhn-Tucker slackness conditions and solve for the two cases.

1. If the ICC is not binding, $U(a ; \underline{w}, \bar{w})>U\left(a^{-} ; \underline{w}, \bar{w}\right)$ and $\mu=0$.

Equations (1), (14) and (15) imply that, in an interior optimum:

$$
q_{a} u^{\prime}(\underline{w}+\bar{\varepsilon})+\left(1-q_{a}\right) u^{\prime}(\underline{w}+\underline{\varepsilon})=q_{a} u^{\prime}(\bar{w}+\bar{\varepsilon})+\left(1-q_{a}\right) u^{\prime}(\bar{w}+\underline{\varepsilon})
$$

This condition is fulfilled iff $\underline{w}=\bar{w}$ which combined with equation (16) implies that:

$$
\underline{w}=\bar{w}=x_{a}=P_{a} \bar{x}+\left(1-P_{a}\right) \underline{x}
$$

For this condition to be feasible, $\left(x_{a}, x_{a}\right)$ must lie in the $a$-effort region.

2. If the ICC is binding, the set of optimal policies in the $a$-effort region is determined by equation (16) and:

$$
U(a ; \underline{w}, \bar{w})=U\left(a^{-} ; \underline{w}, \bar{w}\right)
$$


If this set contains more than one point, the one that is closest to the 45-degree line is preferred ${ }^{11}$. Specifically, to the left of the $\operatorname{IL}(\underline{w}<\bar{w})$ the government prefers the point in this set with maximum $\underline{w}$ and to the right of the IL $(\underline{w}>\bar{w})$ it prefers the point in this set with minimum $\underline{w}$. Indeed, totally differentiating $U(a ; \underline{w}, \bar{w})$ :

$$
d U=\frac{\partial U}{\partial \underline{w}}(a, \underline{w}, \bar{w}) d \underline{w}+\frac{\partial U}{\partial \bar{w}}(a, \underline{w}, \bar{w}) d \bar{w}
$$

and using that on the resources constraint $P_{H} d \bar{w}=-\left(1-P_{H}\right) d \underline{w}$ :

$$
d U=\left[\frac{\partial U}{\partial \underline{w}}(a, \underline{w}, \bar{w})-\frac{1-P_{H}}{P_{H}} \frac{\partial U}{\partial \bar{w}}(a, \underline{w}, \bar{w})\right] d \underline{w}
$$

Finally, using equation (1):

$$
\begin{aligned}
& \frac{d U}{d \underline{w}}=q_{a}\left(1-P_{a}\right)\left(u^{\prime}(\underline{w}+\bar{\varepsilon})-u^{\prime}(\bar{w}+\bar{\varepsilon})\right) \\
&+\left(1-q_{a}\right)\left(1-P_{a}\right)\left(u^{\prime}(\underline{w}+\underline{\varepsilon})-u^{\prime}(\bar{w}+\underline{\varepsilon})\right) \lesseqgtr 0 \quad \text { if } \quad \underline{w} \gtreqless \bar{w}
\end{aligned}
$$

Notice that if $a=L$ this "corner" solution does not strictly belong to $L R$, but it does belong to its frontier, the IL. The government cannot choose a maximum in $L R$, but it can choose the supremum, i.e. the minimum upper bound. By using the supremum rather than the maximum in the government problem we bypass the economically irrelevant indeterminacy that would arise using the maximum.

Summing up, we have proved that the optimal policy in the $a$-effort region is given by equation (18) iff $\left(x_{a}, x_{a}\right)$ lies in this region and by equations (16) and (19), otherwise ${ }^{12}$.

\section{Second step. Determination of the global optimum.}

Corollary 1 and the results in the first step of this proof leave us with three possibilities to consider:

1. $x_{L}<x_{H} \leq w_{c} \Leftrightarrow\left(x_{H}, x_{H}\right) \in H R$ and $\left(x_{L}, x_{L}\right) \in H R$

2. $x_{L} \leq w_{c}<x_{H} \Leftrightarrow\left(x_{H}, x_{H}\right) \in L R$ and $\left(x_{L}, x_{L}\right) \in H R$

3. $w_{c}<x_{L}<x_{H} \Leftrightarrow\left(x_{H}, x_{H}\right) \in L R$ and $\left(x_{L}, x_{L}\right) \in L R$

11 We cannot rule out this possibility since the IL may have negative slope and the resources constraint has a negative slope.

12 As already explained, if more than one point satisfies equations (16) and (19), the one that is closest to the 45-degree line is selected. In what follows, to simplify exposition, we will continue as if there were just one such point or the selection had been done. 
In what follows, we explore the equilibria in each of these three cases:

1. $x_{L}<x_{H} \leq w_{c} \Leftrightarrow\left(x_{H}, x_{H}\right) \in H R$ and $\left(x_{L}, x_{L}\right) \in H R$

In the high-effort region the supremum (or the maximum in this case) is $U\left(H, x_{H}, x_{H}\right)$, since equation (18) applies. In turn, in the low-effort region, the supremum is determined by equations (16) and (19), with $a=L$. Let us identify the supremum conditional on low effort as $\left(\underline{w}_{L}<\bar{w}_{L}\right)$. Notice that $\left(\underline{w}_{L}, \bar{w}_{L}\right) \in H R$, because $U\left(L, \underline{w}_{L}, \bar{w}_{L}\right)=U\left(H, \underline{w}_{L}, \bar{w}_{L}\right)$ and we have assumed that in case of indifference individuals choose high effort. We know that $U\left(H, \underline{w}_{L}, \bar{w}_{L}\right)<U\left(H, x_{H}, x_{H}\right)$, since $\left(x_{H}, x_{H}\right)$ is the constrained optimum in $H R$ when $\left(x_{H}, x_{H}\right) \in H R$. Therefore, we conclude that $U\left(L, \underline{w}_{L}, \bar{w}_{L}\right)<U\left(H, x_{H}, x_{H}\right)$, i.e. the global optimum is a full insurance and high effort equilibrium with policy $\left(x_{H}, x_{H}\right)$, if $\left(x_{H}, x_{H}\right) \in H R$. This is also a necessary condition for a full insurance high effort equilibrium for otherwise the point $\left(x_{H}, x_{H}\right)$ would not be feasible. This proves point 1 in the proposition.

2. $x_{L} \leq w_{c}<x_{H} \Leftrightarrow\left(x_{H}, x_{H}\right) \in L R$ and $\left(x_{L}, x_{L}\right) \in H R$

Equations (16) and (19) apply in both regions and determine incomplete insurance constrained optimums $\left(\underline{w}_{L}<\bar{w}_{L}\right)$ and $\left(\underline{w}_{H}<\bar{w}_{H}\right)$. The point $\left(\underline{w}_{L}<\bar{w}_{L}\right)$ is on IL so $U\left(L, \underline{w}_{L}, \bar{w}_{L}\right)=U\left(H, \underline{w}_{L}, \bar{w}_{L}\right)$. Also $\left(\underline{w}_{L}<\bar{w}_{L}\right)$ is the optimum in $L R$ because it is the supremum of the individuals utility in $L R$, but $\left(\underline{w}_{L}, \bar{w}_{L}\right) \in H R$. In turn, the fact that $\left(\underline{w}_{H}<\bar{w}_{H}\right)$ is the optimum in $H R$ implies that $U\left(H, \underline{w}_{L}, \bar{w}_{L}\right)<U\left(H, x_{H}, x_{H}\right)$, and hence $U\left(L, \underline{w}_{L}, \bar{w}_{L}\right)<$ $U\left(H, x_{H}, x_{H}\right)$. We conclude that there is an incomplete insurance high effort equilibrium in $\left(\underline{w}_{H}<\bar{w}_{H}\right)$ in this case. This proves point 2 (b) in the proposition.

3. $w_{c}<x_{L}<x_{H} \Leftrightarrow\left(x_{H}, x_{H}\right) \in L R$ and $\left(x_{L}, x_{L}\right) \in L R$

$\left(x_{L}, x_{L}\right) \in L R$ implies that equation (18) applies and the constrained optimum in $L R$ is $U\left(L, x_{L}, x_{L}\right)$. In turn $\left(x_{H}, x_{H}\right) \in L R$ implies that in $H R$ equations (16) and (19) apply and the constrained optimum is $U\left(H, \underline{w}_{H}, \bar{w}_{H}\right)$. Either of these constrained optimums can be the global optimum, depending on parameter values. Therefore, we conclude that, if both $\left(x_{L}, x_{L}\right)$ and $\left(x_{H}, x_{H}\right)$ lie in LR, the equilibrium involves full insurance and low effort if $U\left(L, x_{H}, x_{H}\right)>U\left(H, \underline{w}_{H}, \bar{w}_{H}\right)$, and incomplete insurance and high effort if $U\left(L, x_{H}, x_{H}\right) \leq U\left(H, \underline{w}_{H}, \bar{w}_{H}\right)$. These results prove points 2 (a) and 3 in the proposition.

QED

\subsection{The dilemma of formalization}

Proof of Proposition 4. We define the welfare gains from formalization as the difference between the expected utility in a commitment and a discretionary equilibrium. By virtue of proposition 1, we know that the expected utility in the discretionary equilibrium is $u\left(x_{L}+\varepsilon_{L}\right)-L$. Therefore, the welfare gains from formalization are: 


$$
G=E[u(w+\varepsilon) \mid a]-a-\left(u\left(x_{L}+\varepsilon_{L}\right)-L\right)
$$

Adding and subtracting $u\left(x_{a}+\varepsilon_{a}\right)$ and rearranging, we get equation (9). The signs of the three terms follow from the following considerations:

1. $u\left(x_{a}+\varepsilon_{a}\right)-u\left(x_{L}+\varepsilon_{L}\right) \geq 0$ since $a \in\{H, L\}, x_{H}>x_{L}$ and $\varepsilon_{H}>\varepsilon_{L}$.

2. $E[u(w+\varepsilon) \mid a]-u\left(x_{a}+\varepsilon_{a}\right)<0$, because of Jensen's inequality. Indeed, $u($.) is concave, and $E[w+\varepsilon \mid a]=x_{a}+\varepsilon_{a}$.

3. $-(a-L) \leq 0$ since $a \geq L$.

QED

\subsection{Voting on redistribution}

The model in previous sections has no politics. In this section, we present a simple extension of the basic model in which individuals act not only as economic agents, choosing the level of effort, but also as citizens, voting in a referendum and in elections. Their preferences can be represented by the same expected utility functions considered in the previous model. There are two politicians who compete in elections offering redistributive policies. Their only goal is to win the election.

The timing is as follows:

1. There is a referendum on a law enforcement institution.

2. Individuals choose effort.

3. Politicians announce their political platforms.

4. Elections take place.

5. Nature chooses output.

6. The government implements the policies announced in the electoral campaign.

In the first stage, citizens vote on a proposal to build the law enforcement institutions (the judiciary, an independent oversight agency, etc.). This institutional building is a long run investment and as such is assumed to take place before individuals and politicians take any other decision.

In the second stage, individuals choose effort, knowing whether the law enforcement institution was accepted in the referendum.

In the third stage, two politicians present political platforms. Feasible promises depend on the results of the referendum that took place in the first stage. If the law enforcement institution was approved, it will force the government to redistribute only on a pre-committed basis. In this environment, credible political platforms can only condition transfers on the insurable part of income $(w(x))$ and hence disposable income will be $w_{i}=w\left(x_{i}\right)+\varepsilon_{i}$. If the enforcement institution was voted down, the government will be free to redistribute on a discretionary basis, and politicians will be able to choose policies contingent on both components of output: $w_{i}=w\left(x_{i}, \varepsilon_{i}\right)$. 
In the electoral stage, citizens vote for their preferred proposal.

Afterwards, nature chooses output and finally the government implements the policies announced during the campaign. Following a long tradition in political economy (Downs 1957), we assume that politicians can commit to the campaign promises.

We also make the following anonymity assumption:

Assumption 1 (Anonymity). If individuals $i$ and $j$ have pre-transfers income $x_{i}=x_{j}$ and $\varepsilon_{i}=\varepsilon_{j}$, then $w_{i}=w_{j}$.

The anonymity assumption implies that politicians cannot make distinctions among citizens other than those emerging from their different outcomes, represented in our model by insurable and non-insurable income. We make this assumption to rule out the possibility that politicians offer transfers to a subset of voters that conform a minimum winning coalition excluding all the rest. The theme of this paper is not related to political exclusion, so we get rid of this issue with the anonymity assumption. We impose no further constraints on political platforms.

Our main result in this section is summarized in the following proposition.

Proposition 5. There is a political equilibrium in which (i) citizens vote against the law enforcement institution; (ii) individuals choose low effort; and (iii) politicians redistributes all income evenly: $w(x, \varepsilon)=x_{L}+\varepsilon_{L} \forall x, \varepsilon$; if and only if

1. individuals prefer low effort in the commitment equilibrium $\left(\Leftrightarrow x_{L}>w_{c}\right.$ and $\left.U\left(L, x_{L}, x_{L}\right)>U\left(H, \underline{w}_{H}, \bar{w}_{H}\right)\right)$; or

2. individuals prefer high effort in the commitment equilibrium and $H-L-E[u(w+\varepsilon) \mid H]>-u\left(x_{L}+\varepsilon_{L}\right)$.

Proof of Proposition 5. We solve by backward induction. In stage 6, the government is forced to implement the policies announced in the political campaign, so there are no actual decisions at this stage. Nature is not a strategic player and, in stage 5, it simply chooses the level of individual output $x_{i} \in\{\underline{x}, \bar{x}\}$ and $\varepsilon_{i} \in\{\underline{\varepsilon}, \bar{\varepsilon}\}$, based on probabilities $P\left(a_{i}\right)$ and $q\left(a_{i}\right)$.

In stage 4 , citizens vote for the candidate with the policy platform that provides higher expected utility. At this stage individuals have already chosen the level of effort. We first determine the redistributive policy preferred by a citizen who in stage 2 chose effort level $a$ with and without the law enforcement institution:

1. Case 1: the law enforcement institution was approved in the referendum. In this case, considering the constraints that the enforcement institution and the anonymity assumption put on policies, citizens preferred policies solve the following program:

$$
\begin{gathered}
\max _{\{\underline{w}, \bar{w}\}} U(a, \underline{w}, \bar{w}) \\
\text { st }: \int_{0}^{1}\left[P_{a_{i}} \bar{w}+\left(1-P_{a_{i}}\right) \underline{w}\right] d i \leq \int_{0}^{1}\left[P_{a_{i}} \bar{x}+\left(1-P_{a_{i}}\right) \underline{x}\right] d i
\end{gathered}
$$


The first order conditions are ${ }^{13}$ :

$$
\begin{gathered}
q_{a}\left(1-P_{a}\right) u^{\prime}(\underline{w}+\bar{\varepsilon})+\left(1-q_{a}\right)\left(1-P_{a}\right) u^{\prime}(\underline{w}+\underline{\varepsilon})=\lambda \int_{0}^{1}\left(1-P_{a_{i}}\right) d i \\
q_{a} P_{a} u^{\prime}(\bar{w}+\bar{\varepsilon})+\left(1-q_{a}\right) P_{a} u^{\prime}(\bar{w}+\underline{\varepsilon})=\lambda \int_{0}^{1} P_{a_{i}} d i
\end{gathered}
$$

We are characterizing an equilibrium in which all individuals choose the same level of effort: $a=a_{i} \quad \forall i$. Therefore, the FOCs imply:

$$
q_{a} u^{\prime}(\underline{w}+\bar{\varepsilon})+\left(1-q_{a}\right) u^{\prime}(\underline{w}+\underline{\varepsilon})=q_{a} u^{\prime}(\bar{w}+\bar{\varepsilon})+\left(1-q_{a}\right) u^{\prime}(\bar{w}+\underline{\varepsilon})
$$

From this condition and the resource constraint we get that: $\underline{w}=\bar{w}=x_{a}=P_{a} \bar{x}+\left(1-P_{a}\right) \underline{x}$.

2. Case 2: the law enforcement institution was not approved in the referendum. If there is no law enforcement institution, citizens know that the government can condition disposable income on total output and, because of the anonymity assumption, it can only condition disposable income on output, so citizens preferred policies solve the following program:

$$
\begin{aligned}
\max _{w(x, \varepsilon)} q_{a}\left[P_{a} u\left(w(\bar{x}, \bar{\varepsilon})+\left(1-P_{a}\right) u(w(\underline{x}, \bar{\varepsilon}))\right]\right. \\
+\left(1-q_{a}\right)\left[P_{a} u(w(\bar{x}, \underline{\varepsilon}))+\left(1-P_{a}\right) u(w(\underline{x}, \underline{\varepsilon}))\right] \\
s t: q_{a}\left[P_{a} w(\bar{x}, \bar{\varepsilon})+\left(1-P_{a}\right) w(\underline{x}, \bar{\varepsilon})\right] \\
+\left(1-q_{a}\right)\left[P_{a} w(\bar{x}, \underline{\varepsilon})+\left(1-P_{a}\right) w(\underline{x}, \underline{\varepsilon})\right] \leq x_{a}+\varepsilon_{a}
\end{aligned}
$$

where we have used again that $a=a_{i} \forall i$. The first order conditions are:

$$
\begin{aligned}
q_{a} P_{a} u^{\prime}(w(\bar{x}, \bar{\varepsilon})) & =\lambda q_{a} P_{a} \\
q_{a}\left(1-P_{a}\right) u^{\prime}(w(\underline{x}, \bar{\varepsilon})) & =\lambda q_{a}\left(1-P_{a}\right) \\
\left(1-q_{a}\right) P_{a} u^{\prime}(w(\bar{x}, \underline{\varepsilon})) & =\lambda\left(1-q_{a}\right) P_{a} \\
\left(1-q_{a}\right)\left(1-P_{a}\right) u^{\prime}(w(\underline{x}, \underline{\varepsilon})) & =\lambda\left(1-q_{a}\right)\left(1-P_{a}\right)
\end{aligned}
$$

Therefore $w(x, \varepsilon)=x_{a}+\varepsilon_{a}, \forall x, \varepsilon$.

In stage 3, politicians will promise $\underline{w}=\bar{w}=P_{a} \bar{x}+\left(1-P_{a}\right) \underline{x}$, if the law enforcement institution is in place, and $w(x, \varepsilon)=x_{a}+\varepsilon_{a} \forall x, \varepsilon$, otherwise.

13 For the sake of brevity and since the resource constraint is necessarily binding, we impose equality without further discussion. 
In stage 2, individuals choose the effort level. Again, we separately consider the cases with and without the law enforcement institution.

1. Case 1: the law enforcement institution was approved in the referendum. An individual chooses high effort when other individuals choose $a_{i}$ iff

$$
q_{H} u(x+\bar{\varepsilon})+\left(1-q_{H}\right) u(x+\underline{\varepsilon})-H \geq q_{L} u(x+\bar{\varepsilon})+\left(1-q_{L}\right) u(x+\underline{\varepsilon})-L
$$

where $x$ is aggregate insurable per capita income $x=\int_{0}^{1}\left[P_{a_{i}} \bar{x}+\left(1-P_{a_{i}}\right) \underline{x}\right] d i$. By virtue of proposition 2, point 3d, this condition holds iff $x_{H} \leq w_{c}$. Otherwise, the individual will choose low effort.

2. Case 2: the law enforcement institution was not approved in the referendum. In this case, individuals choose low effort since: $u\left(x_{a}+\varepsilon_{a}\right)-H<u\left(x_{a}+\varepsilon_{a}\right)-L$. In stage 1 , individuals vote in the referendum. By virtue of equation (9), citizens will prefer discretion over commitment -which in the voting model is a synonym for no law enforcement institution- if (i) individuals prefer low effort in the commitment equilibrium, or (ii) individuals prefer high effort in the commitment equilibrium and $H-L-E[u(w+\varepsilon) \mid H]>-u\left(x_{L}+\varepsilon_{L}\right)$. According to proposition 3 individuals prefer low effort in the commitment equilibrium iff $x_{L}>w_{c}$ and $U\left(L, x_{L}, x_{L}\right)>U\left(H, \underline{w}_{H}, \bar{w}_{H}\right)$, and prefer high effort otherwise.

QED

We have assumed that elections take place after individuals have chosen effort. For this reason, incentive considerations are not present at this stage and citizens will vote for as much insurance as possible. How much insurance is possible depends though on the institutional environment chosen in the first stage. By voting in the referendum in favor of the law enforcement institution, citizens tie politicians' hands -and in fact also their own hands-, limiting the level of insurance that politicians will be able to promise in the ensuing elections. Hence, the law enforcement institution provides a commitment technology. This is however imperfect, because it does not allow to commit to a fully contingent policy. The institution only allows politicians to commit not to provide insurance on the non-verifiable or truly uncertain component of output. If this component is sufficiently important and risky, individuals are sufficiently risk averse or dislike effort too much, it may not be convenient to lose the flexibility-insurance provided by an unsupervised government. Citizens will then vote against the law enforcement institution and policies will be conducted on a discretionary basis.

In this framework, individuals will not support commitment if discretion provides higher expected utility than commitment. The country will thus have weak enforcement capacity but, unlike in most of the literature on informality, in our model weak enforcement capacity is an endogenous outcome conducive to the desired discretionary policy regime. Weak enforcement capacity is not the ultimate cause of lack of enforcement but a choice citizens make to facilitate "flexibility". 
